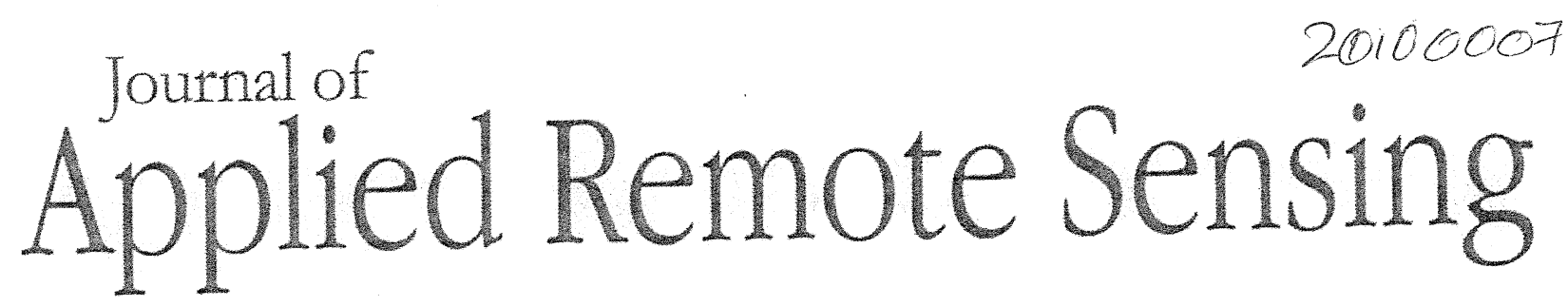

\title{
Spectral compatibility of vegetation indices across sensors: band decomposition analysis with Hyperion data
}

Youngwook Kim Alfredo R. Huete Tomoaki Miura Zhangyan Jiang 


\title{
Spectral compatibility of vegetation indices across sensors: band decomposition analysis with Hyperion data
}

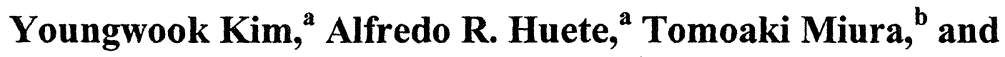 \\ Zhangyan Jiang ${ }^{\mathrm{a}}$ \\ ${ }^{a}$ University of Arizona, Department of Soil, Water, and Environmental Science, \\ Tucson, AZ, 85721 \\ ${ }^{\mathrm{b}}$ University of Hawaii at Manoa, College of Tropical Agriculture and Human \\ Resources, Department of Natural Resources and Environmental Management, \\ Honolulu, HI 96822
}

\begin{abstract}
Vegetation indices (VIs) are widely used in long-term measurement studies of vegetation changes, including seasonal vegetation activity and interannual vegetation-climate interactions. There is much interest in developing cross-sensor/multi-mission vegetation products that can be extended to future sensors while maintaining continuity with present and past sensors. In this study we investigated multi-sensor spectral bandpass dependencies of the enhanced vegetation index (EVI), a 2-band EVI (EVI2), and the normalized difference vegetation index (NDVI) using spectrally convolved Earth Observing-1 (EO-1) Hyperion satellite images acquired over a range of vegetation conditions. Two types of analysis were carried out, including (1) empirical relationships among sensor reflectances and VIs and (2) decomposition of bandpass contributions to observed cross-sensor VI differences. VI differences were a function of cross-sensor bandpass disparities and the integrative manner in which bandpass differences in red, near-infrared (NIR), and blue reflectances combined to influence a VI. Disparities in blue bandpasses were the primary cause of EVI differences between the Moderate Resolution Imaging Spectroradiometer (MODIS) and other course resolution sensors, including the upcoming Visible Infrared Imager / Radiometer Suite (VIIRS). The highest compatibility was between VIIRS and MODIS EVI2 while AVHRR NDVI and EVI2 were the least compatible to MODIS.
\end{abstract}

Keywords: vegetation index, normalized difference vegetation index, enhanced vegetation index, two-band enhanced vegetation index, continuity, VIIRS, MODIS, band decomposition.

\section{Introduction}

A variety of satellite sensors routinely observe the Earth's surface at daily, weekly, and monthly time periods. Monitoring the Earth's biosphere is very important for examining land cover change, agricultural production, natural resource management, and climate change. Consistent normalized difference vegetation index (NDVI) products, of $20+$ years, have been generated from the multiple series of NOAA Advanced Very High Resolution Radiometers (AVHRR) at 1-8 km [1-2], enabling large scale global and regional studies of vegetation photosynthetic activity and biophysical properties [3]. Many studies have related the NDVI to biomass, leaf area index, agriculture and rangeland primary productivity, absorbed photosynthetically-active radiation, phenology variability, and various meteorological and ecological parameters [4-12].

In addition to the AVHRR series of instruments, the Moderate Resolution Imaging Spectroradiometers (MODIS) onboard the Terra and Aqua satellite platforms have routinely generated vegetation index (VI) products since 2000, at multiple resolutions from $250 \mathrm{~m}$ to $\sim 5$ $\mathrm{km}$ at 8-day, 16-day, and monthly intervals. The VEGETATION instrument of the System 
Pour l'Obervation de la Terre (SPOT-VGT) has provided an NDVI 10-day composite product at $\sim 1 \mathrm{~km}$ pixel resolution since 1998. Daily and composited, $1.1 \mathrm{~km}$ NDVI time series are also generated from the Sea-viewing Wide Field-of-view Sensor (SeaWiFS) that has acquired global data since 1997. The Visible/Infrared Imager/Radiometer Suite (VIIRS) sensor, to reside on the future National Polar-orbiting Operational Environmental Satellite System (NPOESS) satellite series, is tasked to generate VI products at $375 \mathrm{~m}$ spatial resolution with 1 day revisit time [13].

The usefulness of NDVI for quantitative long term studies is partly dependent upon the extent to which various sources of noise associated with view angle differences, soil background influences, clouds and cloud shadow, atmospheric influences, and topographic effects may inhibit the detection of surface vegetation changes. In addition, saturation of the vegetation index (VI) signal in high biomass conditions would also restrict quantitative vegetation assessments [14-16]. As one of the MODIS biophysical products, the Enhanced Vegetation Index (EVI) was developed to optimize the vegetation signal by reducing atmospheric influences and canopy background noise and provide improved sensitivity in high biomass regions [17]. The MODIS EVI has been found useful in phenology and gross primary productivity studies over a complete range of biomes [5-7, 9, 18-20].

There have been many studies analyzing the compatibility of NDVI products from new and advanced sensor systems with the existing long-term NDVI time series data [21-32]. Cross-sensor differences have been found to be dependent on spectral bandpass differences and atmospheric condition [22-23, 29, 32-33]. Many of these studies have found empirical cross-sensor linear relationships across sensor datasets, or translation equations, which enable coupling of two or more NDVI datasets. Some studies have further involved cross-sensor comparisons of the relationship between NDVI and biophysical variables [34]. Fensholt et al. (2004) found the dynamic range of the MODIS NDVI was generally much larger than the AVHRR NDVI, along with more serious saturation issues in MODIS NDVI [35].

By contrast, the compatibility of the EVI across different sensor systems has received much less attention in cross-sensor continuity studies, despite the potential complementary benefits of the EVI to the existing long-term NDVI time series, particularly in more densely vegetated areas where NDVI is largely insensitive. Although MODIS EVI shows greater sensitivity in high biomass areas, the scientific link between MODIS EVI and AVHRR NDVI is not straightforward and has not been established. Xiao et al. $(2004,2005)$ found that EVI values derived from MODIS and SPOT-VGT yielded similar and consistent phenology profiles in three different forest biomes in North and South America [36, 37]. Miura et al. (2008) investigated cross-sensor variations in surface reflectances and NDVI using Advanced Spaceborne Thermal Emission and Reflection Radiometer (ASTER) and MODIS data and a two-band version of EVI from ASTER to MODIS EVI [38]. They found the magnitude of systematic differences between scene pairs to be largely independent of geographic location, land cover, and temporal periods.

One important reason for the lower attention placed on EVI sensor continuity is that EVI can only be applied to sensors with a blue band, and most studies have focused on crosssensor comparisons with the AVHRR, in which there is no blue band available for EVI computation. To overcome this problem, Jiang et al. [39] developed a two-band EVI (EVI2) exhibiting nearly identical behavior to the EVI when applied to good quality, atmospherically corrected MODIS data. The EVI2 retains the soil-noise adjustment function as well as improved sensitivity over high biomass regions, as found in the EVI. Although MODIS EVI and EVI2 similarities have been tested and validated at local to global scales, cross-sensor EVI2 studies have generally not been made.

The EVI may be more complex for continuity purposes due to the use of three bands, compared with the two bands needed for NDVI. The EVI equation may thus require stricter coherencies among three bands (blue, red, and NIR), rendering it more difficult to translate across sensor systems $[25,40]$. Since the EVI and NDVI are standard Environmental Data 
Records (EDR) to the future VIIRS sensor, it is of great interest to characterize the compatibilities of the MODIS and VIIRS VIs and their associated blue, red, and NIR bandpass reflectances.

An excellent method to spectrally characterize VIs across multiple sensors is the use of hyperspectral data, such as EO-1 Hyperion data, in which sensor-specific bandpasses and VIs are readily generated for specific scenes and land cover types. EO-1 Hyperion is a pushbroom hyperspectral sensor with $220,10-\mathrm{nm}$ bands covering the spectrum from 400 to $2500 \mathrm{~nm}$ with a nominal spatial resolution of $30 \mathrm{~m}$ (signal to noise: 40) [41]. The Hyperion images are readily convolved into sensor-specific imagery, enabling cross-sensor comparisons of VI values for identical sensor acquisition, illumination and viewing geometries, atmospheric condition, spatial resolution, and environmental surface conditions [22]

In this paper we analyzed cross-sensor EVI, EVI2, and NDVI relationships over a series of course resolution sensor bandpasses, including MODIS, VIIRS, SPOT-VGT, SeaWiFS, and AVHRR, using sensor-specific reflectances convolved from EO-1 Hyperion data acquired over a range of land cover types (grassland, savanna, wetland, riparian, and rainforest).

\section{Materials}

\subsection{Spectral Response Functions}

The normalized spectral response functions of the red, NIR, and blue bandpasses show wide variations across the five sensors examined here (Fig. 1). The AVHRR has the largest bandwidth in the 'red' (570 nm to $700 \mathrm{~nm}$ ), followed by VIIRS, SPOT-VGT, and MODIS, with the SeaWiFS 'red' bandpass being the narrowest (Fig. 1a). Besides bandwidths, there are also center wavelength differences, with SPOT-VGT and SeaWiFS having longer center wavelengths ( $\sim 645 \mathrm{~nm}$ and $\sim 670 \mathrm{~nm}$, respectively) relative to the others (Fig. 1a).

In the NIR spectral region, the AVHRR also has the widest bandwidth (710 nm to 980 $\mathrm{nm})$ that partly encompasses the red-NIR transitional zone $(680-780 \mathrm{~nm})$ and a leaf water absorption region at approximately $940 \mathrm{~nm}$ (Fig. 1b). The MODIS, VIIRS, and SeaWiFS have very similar narrow NIR bands $(\sim 840$ to $880 \mathrm{~nm})$ that are positioned at slightly longer center wavelengths. The SPOT-VGT NIR bandwidth is twice that of MODIS, VIIRS, and SeaWiFS, but considerably smaller than the AVHRR-NIR bandpass (Fig. 1b).

The sensor bandpasses in the blue encompass two disparate wavelength ranges with minimal overlap between them (Fig. 1c). MODIS and SPOT-VGT have their blue bands centered at $\sim 465 \mathrm{~nm}$, whereas the VIIRS and SeaWiFS have blue bands that are centered at $\sim 495 \mathrm{~nm}$. The SPOT-VGT blue band is also much wider than the MODIS counterpart (Fig. 1c). Thus, the MODIS blue band is distinct from VIIRS, with a slight portion of overlap. It should be noted that the AVHRR sensor series do not have a blue band.

\subsection{Hyperion Image Processing}

Three radiometrically-calibrated EO-1 Hyperion (Level 1A) images were used in this study to represent a range of surface land cover characteristics (Table 1). The three images were acquired during the 2001 dry season and included evergreen broadleaf Tropical rainforest at Tapajós (TP); the cerrado biome in Brasilia National Park (BNP); and a transition biome (rainforest, wetland, grassland, cerrado) within Araguaia National Park (ANP). All three sites are primary core validation sites for the Large Scale Biosphere and Atmosphere in Amazon (LBA) experiment. There were minor differences associated with sun/view angles and atmospheric effects across the three scenes $\left(2.85^{\circ} \mathrm{S}-15.65^{\circ} \mathrm{S}\right.$ latitude and $48.03^{\circ} \mathrm{W}-56.43^{\circ} \mathrm{W}$ longitude). Sensor view zenith angles varied slightly from $2.1^{\circ}$ to $4.6^{\circ}$, while solar zenith angles varied from $38.1^{\circ}$ to $49.2^{\circ}$. Aircraft and ground surveys were conducted within 1 week 
of the scene acquisition dates, which found and identified a range of land cover types at various locations that corresponded to a total of 520 pixels across the three images used in the
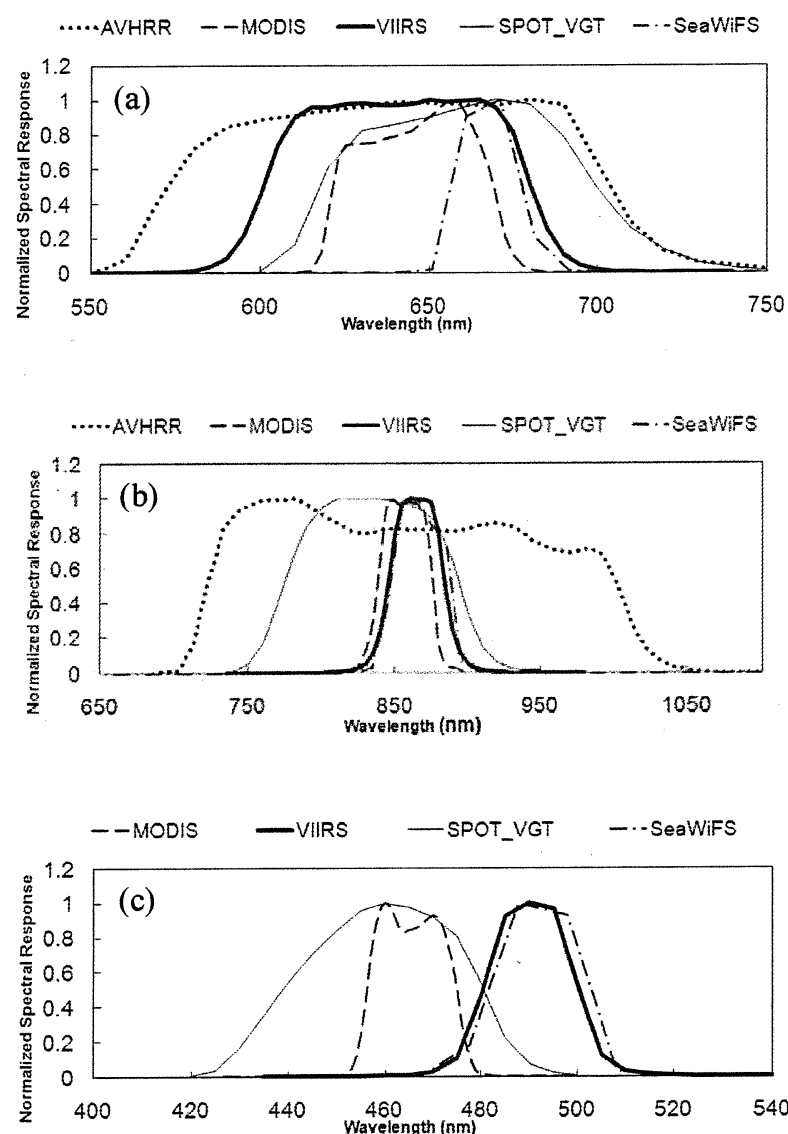

Fig. 1. Normalized spectral response functions of MODIS, VIIRS, AVHRR, SPOT-VGT, and SeaWiFS sensors in (a) red, (b) NIR, and (c) blue bands.

analyses described below [22]. In all the three scenes, atmospheric corrections were accomplished over clear, cloud-free, and low aerosol atmospheres. Pixel size and location were consistent for all spectrally simulated sensors and their bandpasses, since the convolved datasets utilized the same pixels at different bandpasses. Thus, in this study we assume all data are good quality observations with negligible noise and contamination bias, and with VI variations primarily resulting from cross-sensor spectral bandpass differences. We did not consider differences in spatial resolutions and atmospheric correction schemes in this study, which exist in the actual data products.

Top of atmosphere (TOA) radiances from Hyperion were first spectrally convolved into the bandpasses of MODIS, NOAA-14 AVHRR, NPOESS VIIRS, SPOT-VGT, and SeaWiFS using their respective spectral response functions. The convolved radiances were atmospherically corrected with 6S to obtain top of the canopy (TOC) spectral reflectances [42]. The 6S model corrections were constrained with site-specific atmospheric parameter values retrieved from available data sources. Total ozone thickness and column water vapor 
contents were extracted from the MODIS daily atmosphere product (MOD08) for the three [43]. The Tropical atmosphere model was used for the TP and ANP scenes and the

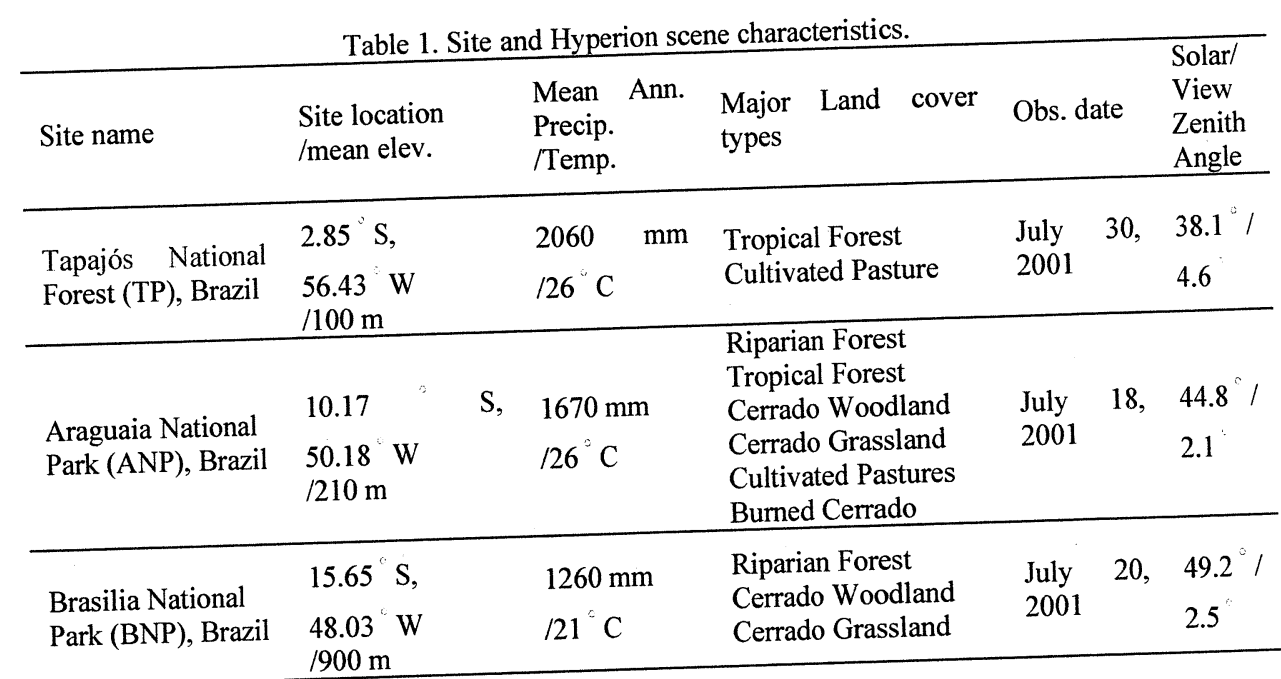

mid-latitude winter atmosphere model was used for the BNP scene. The continental aerosol model with a $100 \mathrm{~km}$ visibility $(0.1$ optical thickness at $550 \mathrm{~nm})$ was used in all three scenes, as they were all acquired under very clear sky conditions [22]. Local ground elevations of the three study areas were obtained from GTOPO30, a global digital elevation model (DEM) with a horizontal grid spacing of 30 arc seconds $(\sim 1 \mathrm{~km})[44]$.

\section{Analysis Methods}

We evaluated cross-sensor relationships among reflectances and VIs obtained from the moderate resolution sensor bandpasses, including the compatibility of the EVI with EVI2. The EVI and EVI2 have the forms,

$$
E V I \text { or } E V I 2=G \times \frac{\rho_{N I R}-\rho_{\mathrm{Re} d}}{L+\rho_{N I R}+C_{1} \times \rho_{\mathrm{Re} d}-C_{2} \times \rho_{\text {Blue }}} \text {, }
$$

where $\rho_{N I R}, \rho_{\operatorname{Re} d}$, and $\rho_{\text {Blue }}$ are the atmospherically or partially corrected surface reflectances for the NIR, red, and blue bands, respectively, $L$ is the canopy background adjustment factor, and $C_{1}, C_{2}$ are the coefficients for the aerosol resistance term. The values of the coefficients are $L=1, C_{1}=6, C_{2}=7.5$, and $G$ (gain factor) $=2.5$ for the EVI [17]. For the EVI2, these are $L=1, C_{1}=2.4, C_{2}=0$, and $G=2.5$ [39].

Agreements in reflectances across different sensor bandpasses were first examined using Pearson's correlation coefficients. The coefficients were computed for all possible combinations of the five sensors for each of the blue, red, and NIR bands. We further examined agreements between reflectances as well as VIs across different sensor bandpasses with regression analysis. A preliminary analysis indicated very strong linear relationships of these variables and, thus, a simple linear model was used. For this analysis, agreement was defined as the closeness of the derived slope and intercept values to 1.0 and zero, respectively. Three sets of regression analyses were performed. First, we examined agreements between VIIRS, SPOT-VGT, SeaWiFS, or AVHRR and MODIS for reflectances and VIs:

$$
X_{S}=a X_{M O D I S}+b+\varepsilon
$$


where $X_{S}$ is the reflectance or VI of a specific sensor, $X_{M O D I S}$ is the MODIS counterpart, and $\varepsilon$ is the unexplained residual error. Second, agreements between the EVI2 and the EVI were evaluated for MODIS, VIIRS, SPOT-VGT, and SeaWiFS:

$$
E V I 2_{S}=a E V I_{S}+b+\varepsilon \text {, }
$$

where $\varepsilon$ is the unexplained residual error.

Cross-sensor differences were also computed and evaluated by subtracting sensor-specific values (reflectances and VIs) from the corresponding MODIS values. The mean absolute difference (MAD) between these values from the two sensors was computed as a quantitative measure of sensor differences;

$$
M A D=\frac{\sum_{i=1}^{n}\left|X 1_{i}-X 2_{i}\right|}{N},
$$

where $X 1=$ reflectances or VIs for sensor (1), X2 = MODIS reflectance or VI and $N$ is the number of total samples.

We used the empirical linear regression equations (Tables 2 and 3 ) to evaluate the feasibility of modeling cross-sensor differences, and computed the Root Mean Square Error (RMSE) to assess the modeling accuracies of cross-sensor reflectance and VIs. The RMSE is calculated as:

$$
R M S E=\sqrt{\frac{\sum(\hat{\theta}-\theta)^{2}}{N}},
$$

where $\hat{\theta}$ is the predicted value by applying the simple linear translation equation, $\theta$ is the observed convolved value. We also computed the MAD between the predicted and the observed values $\left(\mathrm{MAD}^{\mathrm{a}}\right)$ as a quantitative measure of the accuracy of using empirical linear inter-sensor translation equations;

$$
M A D^{a}=\frac{\sum_{i=1}^{n}\left|\hat{X} 1_{i}-X 2_{i}\right|}{N}
$$

where $\hat{X} 1$ is the predicted reflectances or VIs by applying the simple linear translation equation and $X 2$ is MODIS reflectance or VIs.

The above analysis characterizes cross-sensor VI variations resulting from the combined effect of differences in spectral response functions in two or three bands. To better characterize the mechanisms of cross sensor VI differences, we assessed VI spectral dependencies on the individual red, NIR, and blue bandpasses.

Due to relatively small reflectance deviations between MODIS bands with other sensor bands $(<0.06$, see Fig. 2$)$, VI deviations between sensors $\left(\Delta V I=V I_{\text {SENSOR }}-V I_{\text {MODIS }}\right)$ can be closely approximated by an error propagation equation. We employed the following equation to investigate the contribution of each band to overall VI differences across sensors $[45,46]$.

$$
\Delta V I \approx \frac{\partial V I}{\partial \rho_{\mathrm{Re} d}} \Delta \rho_{\mathrm{Re} d}+\frac{\partial V I}{\partial \rho_{N I R}} \Delta \rho_{N I R}+\frac{\partial V I}{\partial \rho_{\text {Blue }}} \Delta \rho_{\text {Blue }} .
$$

The negligible errors caused by the approximation in Eq. (7) are discussed later in section 4.4. Eq. (7) indicates that cross-sensor deviations in VI consist of three band components with each band component as a product of the individual band deviations between the MODIS sensor and the other sensor (e.g. $\Delta \rho_{\mathrm{Re} d}$ ) and the partial derivative of the VI at the average 
reflectance of MODIS and the other sensor (e.g. $\partial V I / \partial \rho_{\text {Red }}$ ). For a two band VI without a blue band, the third term in the right hand side of Eq. (7) is zero since the partial derivative on the blue reflectance is zero. The partial derivatives of EVI, EVI2 and NDVI on reflectances are listed in Appendix A. The band component deviations were plotted against the overall cross-sensor VI deviations in order to investigate which bands have the strongest sensitivity for each VI and sensor bandpass combination.

\section{Results}

\subsection{Cross sensor reflectance relationships}

The cross-sensor reflectance relationships between VIIRS, SeaWiFS, SPOT-VGT, and AVHRR bandpasses and the respective MODIS band reflectances are summarized in Table 2. Despite the large bandwidth differences in the red and NIR, and the disparate, nonoverlapping sets of blue bandpasses (Fig. 1), cross-sensor reflectance relationships among VIIRS, SeaWiFS, MODIS, SPOT-VGT, and AVHRR bandpasses were all linear and highly correlated over the wide range of vegetation conditions analyzed here $\left(\mathrm{r}^{2}>0.97\right)$ (not shown). However, there were considerable differences in their slopes $(0.85$ to 1.20$)$ with slight variations in intercepts $(+/-0.01)$ (Table 2). Slope deviations from the 1:1 line can result in large differences in cross-sensor VI values, despite strong reflectance correlations.

Table 2. Cross-sensor reflectance translation equations with MODIS using simple linear regression $(\mathrm{n}=520$, over 3 scenes).

\begin{tabular}{l|l|l|l|l}
\hline \multicolumn{2}{c|}{} & \multicolumn{3}{l}{ MODIS (x) } \\
\cline { 3 - 5 } \multicolumn{2}{c|}{} & Red & NIR & Blue \\
\hline \multirow{4}{*}{ VIIRS } & Slope & 0.981 & 0.999 & 1.185 \\
\cline { 2 - 5 } & Intercept & 0.001 & 0.001 & -0.010 \\
\cline { 2 - 5 } & $\mathrm{r}^{2}$ & 0.999 & 0.999 & 0.978 \\
\hline \multirow{4}{*}{ SPOT-VGT } & Slope & 1.010 & 0.965 & 1.005 \\
\cline { 2 - 5 } & Intercept & 0.002 & -0.005 & 0.004 \\
\cline { 2 - 5 } & $\mathrm{r}^{2}$ & 0.999 & 0.999 & 0.994 \\
\hline \multirow{4}{*}{ SeaWiFS } & Slope & 1.0340 & 0.988 & 1.203 \\
\cline { 2 - 5 } & Intercept & -0.004 & 0.001 & -0.013 \\
\cline { 2 - 5 } & $\mathrm{r}^{2}$ & 0.996 & 0.999 & 0.978 \\
\hline \multirow{4}{*}{ AVHRR } & Slope & 0.846 & 0.902 & - \\
\cline { 2 - 5 } & Intercept & 0.008 & -0.002 & - \\
\cline { 2 - 5 } & $\mathrm{r}^{2}$ & 0.971 & 0.984 & - \\
\hline
\end{tabular}

The relationship is $X_{\mathrm{SENSOR}}=a X_{\mathrm{MODIS}}+b$,

MODIS bandpass reflectance relationships in the red and NIR with the corresponding bands of the other sensors mostly had slopes close to 1, except between MODIS and AVHRR (slopes of 0.85 and 0.90 , respectively). The only other large cross-sensor slope departure from 1 , was between MODIS and SeaWiFS in the red (slope $=1.04$ ).

Cross-sensor NIR relationships were also weakest between MODIS and AVHRR $\left(\mathrm{r}^{2}=\right.$ 0.98 ; slope $=0.90$ ), resulting in a $10 \%$ negative bias attributed to the very wide AVHRR NIR bandpass (Fig. 1b). The NIR reflectance values from MODIS were typically greater than the NIR reflectances from all other sensors with regression slopes generally lower than one, and intercepts near zero (Table 2).

Blue bandpass reflectance relationships between MODIS and SPOT-VGT exhibited a slope of one (1.005) and $\mathrm{r}^{2}=0.994$, as expected from their similar spectral response functions (Fig. 1c). Blue bandpass relationships between MODIS with VIIRS and SeaWiFS were 
strongly correlated $\left(r^{2}=0.978\right)$, but exhibited strong slope deviations from the 1:1 line (slopes of $\sim 1.2$ ), which may potentially impact on the three-band EVI values.

\subsection{Cross-sensor reflectance deviations}

To assess cross-sensor reflectance variations between MODIS with VIIRS, SPOT-VGT, and SeaWiFS, we plotted cross-sensor differences $\left(X_{\text {SENSOR }}-X_{\text {MODIS }}\right)$ over a range of MODIS reflectance values (Fig. 2). Reflectance deviations between VIIRS and MODIS were strongest in the blue and generally negligible in the red and NIR bands (Fig. 2a). VIIRS blue reflectances were mostly negatively biased, relative to MODIS, and their differences ranged between -0.01 to +0.01 , with a MAD of 0.004 (Table 4). Over a very narrow range of the MODIS blue reflectances (0.02-0.03), there were strong MODIS-VIIRS blue deviations, as shown by the steep slope in Fig. 2a. In contrast, the VIIRS red and NIR reflectance deviations from MODIS were much lower with a range of variations between -0.003 and +0.004 , and MAD values near 0.001 .

In contrast, MODIS and SPOT-VGT reflectance differences were dominant in the NIR (Fig. 2b). SPOT- VGT red and blue reflectances were slightly higher, while NIR reflectances were considerably lower than MODIS equivalent reflectances $(\sim 5 \%$ lower) (Fig. $2 b)$. The range of NIR deviations varied from near zero to -0.02 with an overall MAD value of 0.0129 (Table 4). The MAD in the blue was similar to that found with the VIIRS (MAD 0.004) (Fig. 2b, Table 4).
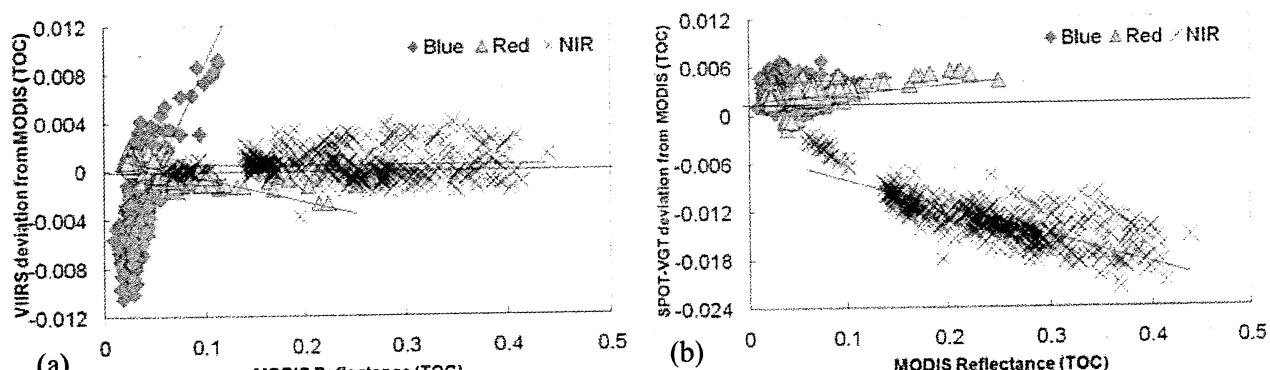

(a) Modis Reflectance (TOC)
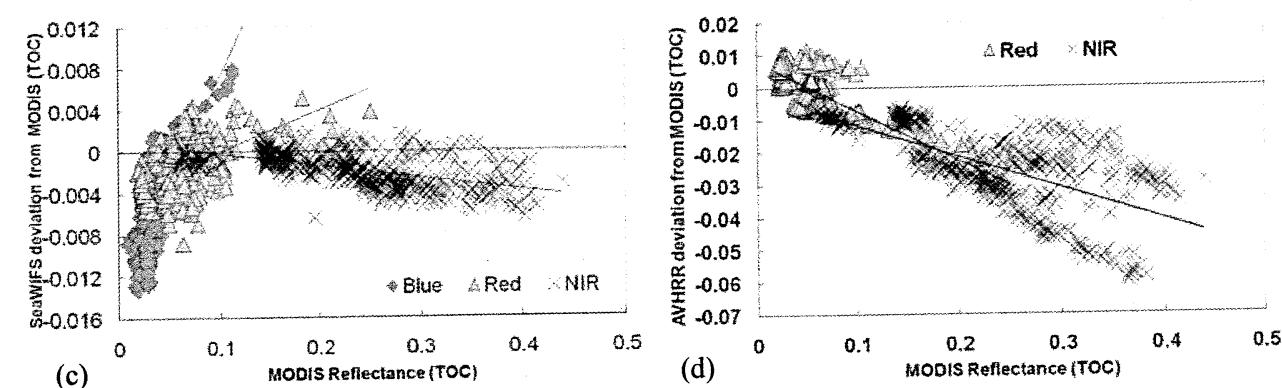

Fig. 2. Sensor reflectance deviations from MODIS reflectance (TOC) using a set of spectrallyconvolved Hyperion images.

Reflectance deviations between the SeaWiFS and MODIS appeared very similar to those shown between the VIIRS and MODIS with the dominant difference in the blue (Fig. 2c). The SeaWiFS red reflectance deviations $(-0.007$ to +0.005$)$ were scattered around zero values (the zero line), with a higher MAD value of $\sim 0.0027$, while the SeaWiFS NIR reflectance deviations were distributed similarly as with the VIIRS, but with mostly negative bias and higher MAD value of 0.002 (Fig. 2c, Table 4). The blue reflectance deviations were mostly 
negative, with a range between -0.013 to +0.013 , and a larger MAD value $(\sim 0.0065)$ than found with the VIIRS.

The AVHRR sensor reflectances had the largest deviations from MODIS reflectances in both the red and NIR, with MAD values of 0.006 and 0.025 , respectively. NIR deviations were particularly pronounced and increasingly negatively biased with increasing NIR reflectances (Fig. 2d). For a given MODIS NIR reflectance of 0.30 , the AVHRR equivalent NIR reflectance varied from less than 0.01 to as high as 0.05 ( $16 \%$ decrease). The AVHRR red reflectances were mostly biased positively and showed the highest overall red reflectance deviations from MODIS.

For average conditions, the accuracy of MODIS reflectances is 0.007 reflectance units or $7 \%$ relative errors, which result from errors in calibration and errors of the input parameters of the atmospheric correction model (6S) including surface air pressure, ozone, water vapor, aerosol optical depth and aerosol model [47]. The NIR MAD values were larger than the average accuracy (0.007) except for the VIIRS sensor (Table 4). But the red and blue MAD values were slightly smaller than the average accuracy (Table 4).

\subsection{Cross-sensor VI analysis}

All cross-sensor VI relationships (NDVI, EVI, EVI2) showed strong coefficients of determination values $\left(r^{2}>0.99\right.$ in Table 3$)$. Slopes of the cross-sensor relationships, however, considerably varied and ranged from 0.92 (MODIS-AVHRR) to 1.05 (MODIS-SeaWiFS). Variations in cross-sensor intercepts were also important and ranged from -0.05 (MODISSeaWiFS) to +0.01 (MODIS-AVHRR).

VI deviations between VIIRS and MODIS were mostly within -0.04 to +0.02 , and tended to go from positive to negative with increasing vegetation (VI values) (Fig. 3a). The greatest deviation was with the EVI $(M A D=0.012)$ and least with EVI2 (MAD =0.003) (Table 4). There was little bias in the 2-band VIs, while differences between sensor EVI values increased negatively with increasing EVI. NDVI and EVI2 were better aligned between MODIS and VIIRS sensors than the EVI (Fig. 3a).

SPOT-VGT VI values were lower than MODIS values for the three VIs, with the highest differences at intermediate VI values (Fig. 3b). Overall, EVI, EVI2, and NDVI differences

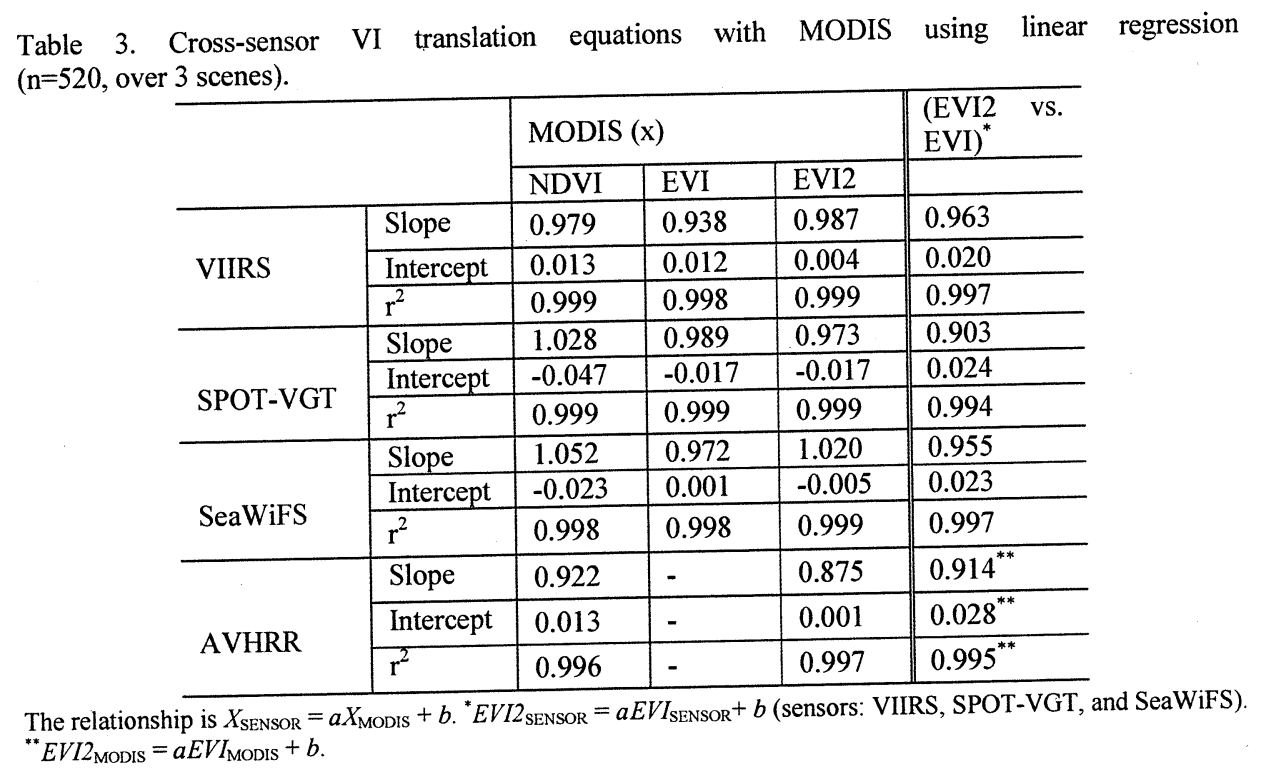



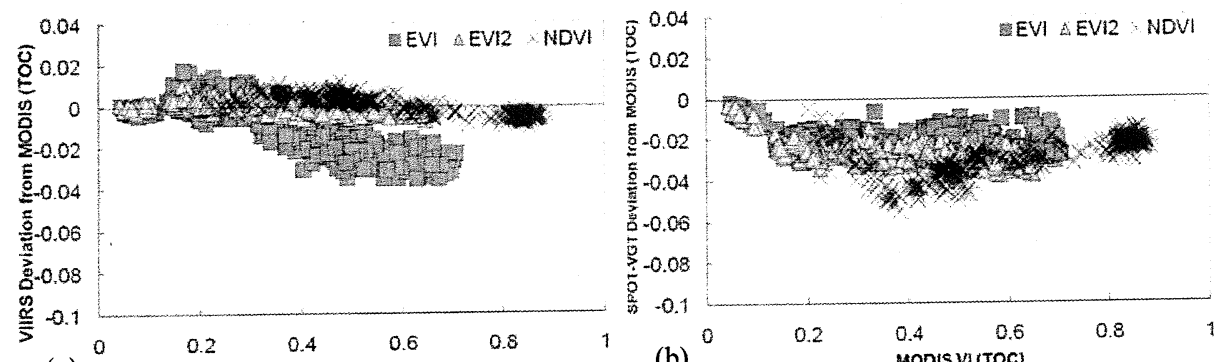

(a)

(b)
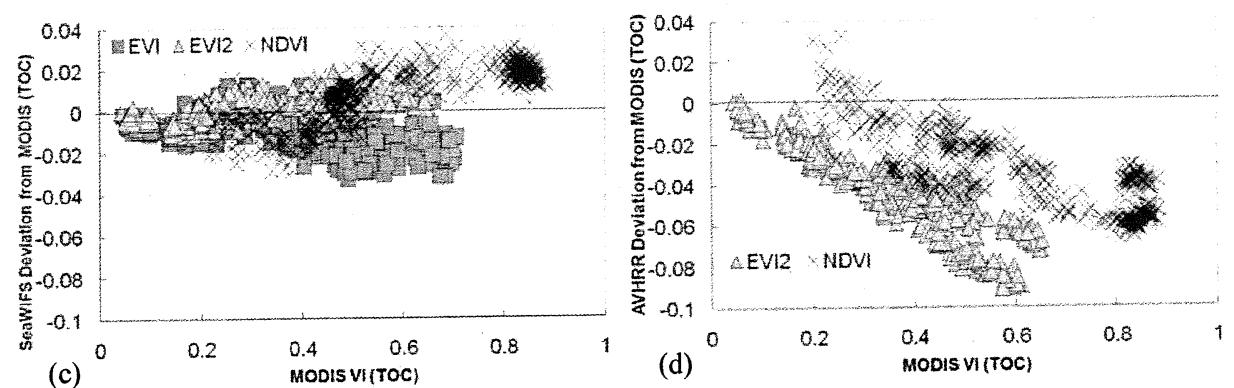

(d)

Fig. 3. Sensor VIs deviations from the MODIS (TOC) using a set of spectrally-convolved Hyperion images.

between SPOT-VGT and MODIS were greater than found between VIIRS and MODIS. Sensor differences were highest with the NDVI, which exceeded 0.05 units (MAD $=0.030$ ), while in this case, the smallest differences were found in the 3-band EVI (MAD $=0.021)$ (Table 4). This suggests that deviations from individual bands may counteract or buffer one another.

VI deviations between SeaWiFS and MODIS resembled those between VIIRS and MODIS for the EVI and EVI2, however, NDVI differences were much larger and biased toward higher values with SeaWiFS bandpasses, particularly at high NDVI values (MAD = 0.015 ) (Fig. 3c, Table 4). SeaWiFS EVI deviations were negatively biased, similar to what was found with VIIRS, an expected result given the similar blue bands of VIIRS and SeaWiFS. The overall MAD values between SeaWiFS and MODIS were 0.011 (EVI), 0.005 (EVI2), and 0.014 (NDVI). In this case the SeaWiFS and MODIS EVI2 values were more aligned than the 3-band EVI.

VI deviations between AVHRR and MODIS were the largest among all sensors analyzed, with an overall range of differences between -0.08 and +0.02 (Fig. 3d). Both AVHRR-NDVI and AVHRR-EVI2 increasingly deviated from MODIS values with increasing vegetation amounts, and with strong negative biases. Inter-sensor EVI2 deviations were higher than NDVI, with MAD values of 0.041 (EVI2) and 0.036 (NDVI) (Table 4). The lower AVHRRVI values corresponded to the same pattern of lower NIR values between the two sensors (Fig. 2d). The strong cross sensor differences between AVHRR and MODIS require corrections for VI continuity purposes and applications, however, the scatter in AVHRR VI values reveal at least two separate and divergent patterns due to lower vegetated pasture pixels, suggesting that more than empirical adjustments would be needed to ensure continuity between MODIS and AVHRR data.

Table 4 summarizes the MAD values, computed from the observed convolved values, and $\mathrm{MAD}^{\mathrm{a}}$ values, derived from modeling cross-sensor differences with empirical translation 
blue reflectances were greatly reduced, by a factor of $2(46 \%)$ and $4(29 \%)$, relative to actual MAD values. $\mathrm{MAD}^{\mathrm{a}}$ values between MODIS and modeled SPOT-VGT NIR reflectances decreased by over a factor of $8(12 \%)$ relative to actual MAD values. The MAD $^{\mathrm{a}}$ values between MODIS and modeled AVHRR red and NIR reflectances were reduced by $1 / 3(67 \%)$ and $2 / 3(32 \%)$, respectively.

Table 4 Cross-sensor MAD and MAD ${ }^{\mathrm{a}}$ before and after the translation and RMSE analyses after the translation $(n=520$, over 3 scenes).

\begin{tabular}{|c|c|c|c|c|c|c|c|c|}
\hline & & \multicolumn{6}{|c|}{ MODIS for MAD/Converted sensor for $\mathrm{MAD}^{\mathrm{a}}$ and RMSE } & \multirow[t]{2}{*}{$\left(\mathrm{EVI} 2\right.$ vs. EVI) ${ }^{*}$} \\
\hline & & Red & NIR & Blue & NDVI & EVI & EVI2 & \\
\hline \multirow{4}{*}{ VIIRS } & MAD & 0.0007 & 0.0010 & 0.0041 & 0.0048 & 0.0118 & 0.0027 & 0.0108 \\
\hline & $\mathrm{MAD}^{\mathrm{a}}$ & 0.0004 & 0.0009 & 0.0019 & 0.0022 & 0.0052 & 0.0018 & 0.0077 \\
\hline & VAR & $57 \%$ & $90 \%$ & $46 \%$ & $46 \%$ & $44 \%$ & $67 \%$ & $71 \%$ \\
\hline & RMSE & 0.0005 & 0.0012 & 0.0023 & 0.003 & 0.0066 & 0.0023 & 0.0092 \\
\hline \multirow{4}{*}{ SPOT-VGT } & MAD & 0.0022 & 0.0129 & 0.0041 & 0.0298 & 0.0207 & 0.0255 & 0.0236 \\
\hline & $\mathrm{MAD}^{\mathrm{a}}$ & 0.0007 & 0.0015 & 0.0008 & 0.0053 & 0.0042 & 0.0033 & 0.0154 \\
\hline & VAR & $32 \%$ & $12 \%$ & $20 \%$ & $18 \%$ & $20 \%$ & $13 \%$ & $65 \%$ \\
\hline & RMSE & 0.0010 & 0.0019 & 0.0011 & 0.0074 & 0.0054 & 0.0043 & 0.0189 \\
\hline \multirow{4}{*}{ SeaWiFS } & MAD & 0.0027 & 0.0020 & 0.0065 & 0.0145 & 0.0108 & 0.0048 & 0.0103 \\
\hline & $\mathrm{MAD}^{\mathrm{a}}$ & 0.0017 & 0.0011 & 0.0019 & 0.0070 & 0.0070 & 0.0033 & 0.0091 \\
\hline & VAR & $63 \%$ & $55 \%$ & $29 \%$ & $48 \%$ & $65 \%$ & $69 \%$ & $88 \%$ \\
\hline & RMSE & 0.0021 & 0.0014 & 0.0024 & 0.0087 & 0.0093 & 0.0041 & 0.0110 \\
\hline \multirow{4}{*}{ AVHRR } & MAD & 0.0055 & 0.0249 & - & 0.0356 & - & 0.0411 & $0.0193^{* *}$ \\
\hline & $\mathrm{MAD}^{\mathrm{a}}$ & 0.0037 & 0.0079 & - & 0.0097 & - & 0.0059 & $0.0134^{* *}$ \\
\hline & VAR & $67 \%$ & $32 \%$ & - & $27 \%$ & - & $14 \%$ & $69 \%$ \\
\hline & RMSE & 0.0044 & 0.0094 & - & 0.0114 & - & 0.0078 & $0.0156^{* *}$ \\
\hline
\end{tabular}

$\mathrm{MAD}$ is calculated before translation. $\mathrm{MAD}^{a}$ and RMSE are derived from the observed value and the predicted value using the inter-sensor translation equation between a sensor and MODIS, or EVI and EVI2. "EVI2 $2_{\text {SENSOR }}=$ $a \mathrm{EVI}_{\mathrm{SENSOR}}+b$ (sensors: VIIRS, SPOT-VGT, and SeaWiFS). ${ }^{* *} \mathrm{EVI}_{\mathrm{MODIS}}=a \mathrm{EVI}_{\mathrm{MODIS}}+b . \mathrm{VAR}=\mathrm{MAD}^{\mathrm{a}} / \mathrm{MAD}$.

We also found large improvements in VI compatibility and continuity between sensor bandpasses through the empirical cross-sensor reflectance translation equations. Agreement in VI values between MODIS and VIIRS were improved by $\sim 50 \%$ for EVI and NDVI, and by $33 \%$ for EVI2. This reduction in VI differences was about the same between MODIS and SeaWiFS. There were more dramatic reductions in VI differences between MODIS and SPOT-VGT as well as between MODIS and AVHRR with the application of sensor translation functions, with NDVI and EVI2 differences reduced by factors of 8 (EVI2) and 4 (NDVI) (Table 4). In all sensor cases analyzed, the modeled EVI2 yielded the least crosssensor VI differences. In the case of continuity between EVI and EVI2, their compatibility was also improved by 10 to $35 \%$ through modeled linear translations, with the lowest MAD value of 0.008 for MODIS and VIIRS (and lowest RMSE=0.009) (Table 4).

\subsection{Bandpass reflectance component factors}

The above VI analyses show that continuity and differences across sensors are a combined result of individual bandpass influences on the VI. To further assess the factors responsible for the observed VI differences, we decomposed cross-sensor VI deviations, using Eq. (7), into their individual band component deviations. The sum of component deviations for each VI and each sensor was first evaluated against the observed VI deviations in order to evaluate the model error in Eq. (7). All relative errors were less than $0.26 \%$, indicating that VI deviations can be decomposed into their band components precisely with Eq. (7) (Fig. 4).

\subsubsection{NDVI band component deviations (2-band)}

The individual bandpass factors responsible for NDVI differences between MODIS and the other sensors were first examined (Fig. 5). Overall differences in NDVI between VIIRS and 


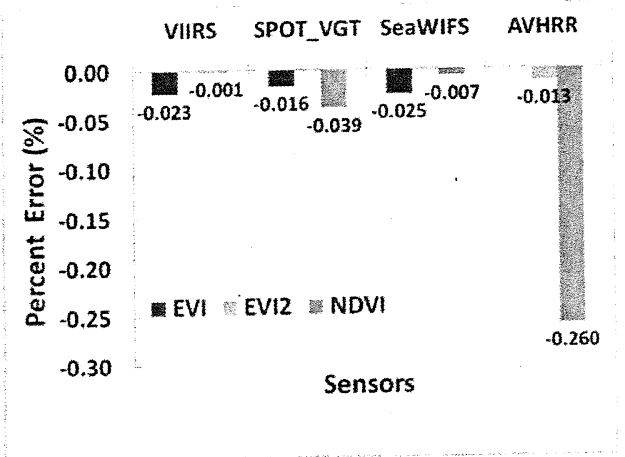

Fig. 4. The average of percent errors (\%) of the modeled VI deviations compared with the observed VI deviations. Percent error $=100^{*}($ (modeled VI deviation)-(observed VI deviation $\left.)\right) /$ (observed VI deviation).

MODIS were relatively small, within a range of $+/-0.010$. As seen in Fig. $5 \mathrm{a}$, these differences were primarily associated with bandpass differences in the red, while NIR bandpass differences contributed very little to observed NDVI differences. This was particularly evident over the range where VIIRS NDVI was less than MODIS NDVI (NDVI deviation $<0$ ), in which case red bandpass differences controlled all VI variations (Fig. 5a).

Red sensor bandpass differences also controlled NDVI differences between MODIS and SeaWiFS, with cross-sensor NIR bandpass differences having a negligible effect (Fig. 5b). The range of NDVI differences between SeaWiFS and MODIS (+/-0.03), however, was three times that found between VIIRS and MODIS $(+/-0.01)$, as a result of the more disparate alignment of red bandpasses between MODIS and SeaWiFS, relative to MODIS and VIIRS (Fig. 1a). By contrast, the NIR bandpasses of VIIRS and SeaWiFS were nearly identical with each other and matched fairly with that from MODIS (Fig. 1b), hence its insignificant contribution to observed NDVI differences.

NDVI differences between MODIS and SPOT-VGT ranged from -0.050 to -0.005 , equivalent to the range found between MODIS and SeaWiFS, but in this case, NIR bandpass differences were primarily responsible for NDVI differences, and red bandpass differences had only a secondary effect (Fig. 5c). NDVI values from SPOT-VGT were lower than MODIS NDVI with both red and NIR bandpass differences additively contributing to lower SPOT-VGT NDVI values. As shown in Figs. 1a, b, NIR bandpass differences between SPOT-VGT and MODIS are much larger than red bandpass differences.

The largest sensor differences in NDVI occurred between AVHRR and MODIS, with a range of nearly $0.100(-0.065$ to +0.030$)$. For a large range of resulting NDVI differences (from -0.03 and +0.03 ), red and NIR bandpass differences showed counteracting influences, with red bandpass deviations contributing a positive bias of $\sim 0.050$ to NDVI differences and NIR bandpass deviations contributing an offsetting $\sim 0.050$ negative bias, thus the very strong bandpass effects canceled one another (Fig. 5d). At the highest NDVI values, AVHRRMODIS NDVI differences became increasingly negative. Furthermore, at the maximum NDVI difference between AVHRR and MODIS $(-0.065)$, red bandpass deviations no longer had a positive influence, and both red and NIR additively contributed to the negative bias.

\subsubsection{EVI band component deviations (3-band)}

The EVI is expected to exhibit more complex sensor bandpass behavior owing to the differential influences of three bands. EVI differences between the VIIRS and MODIS sensor bandpasses ranged from -0.035 to +0.015 , and were primarily controlled by sensor bandpass 

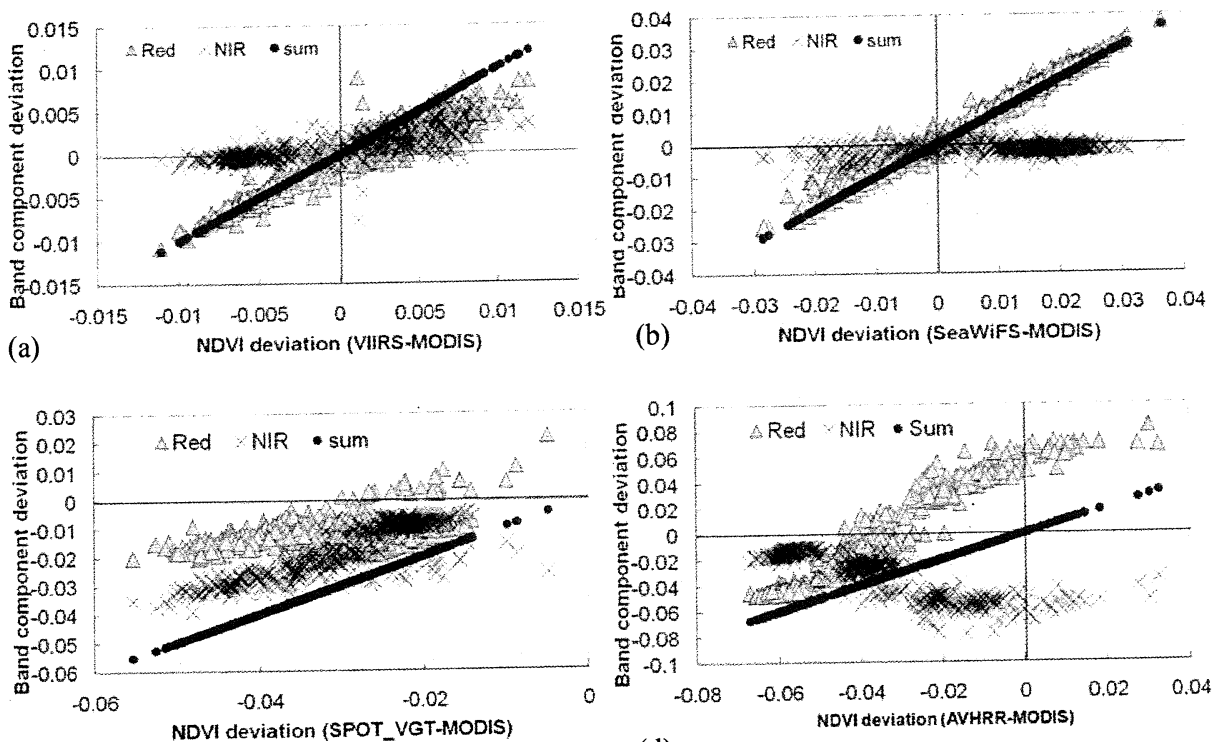

(c)

(d)

Fig. 5. Relationships between NDVI deviations and NDVI band component deviations for (a) VIIRSMODIS; (b) SeaWiFS-MODIS; (c) SPOT_VGT-MODIS; (d) AVHRR-MODIS comparisons.

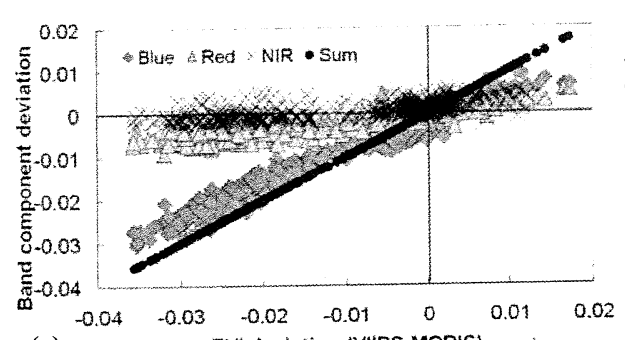

(a) EVI deviation (VIIRS-MODIS)
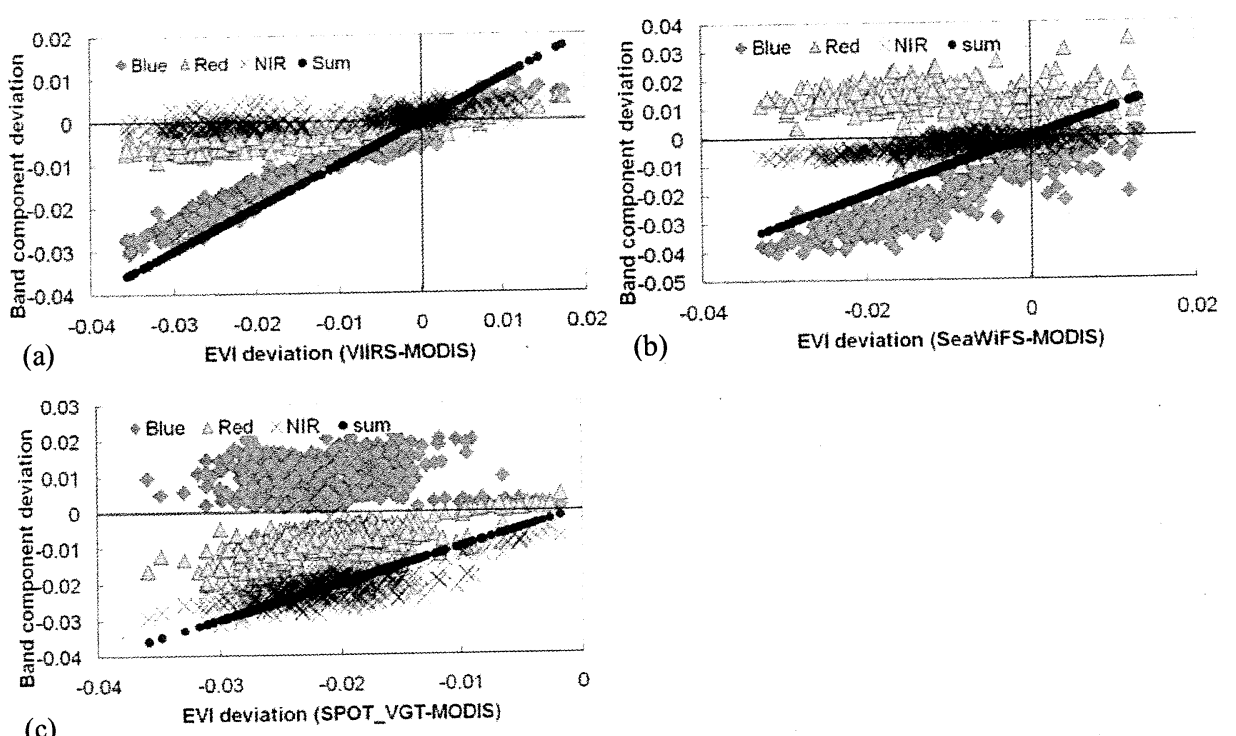

(c)

Fig. 6. Relationships between EVI deviations and EVI band component deviations for (a) VIIRSMODIS; (b) SeaWiFS-MODIS; (c) SPOT_VGT-MODIS comparisons. 
differences in the blue, which increased with increasing amounts of vegetation (negative EVI deviation in Fig. 6a). By contrast, NIR bandpass differences had a slight positive bias on VIIRS EVI values while red bandpass differences resulted in a slight negative bias, with the influence from both bands nearly constant through the range of vegetation amounts and conditions analyzed here (Fig. 6a). Thus, the sensor EVI differences were almost totally attributed to the lack of congruency between the VIIRS and MODIS blue spectral bandpasses (Fig. 1c), accounting for over $90 \%$, on average, of total observed EVI variations.

A similar pattern of EVI differences was found between SeaWiFS and MODIS, but with a smaller overall range of differences (from -0.03 to +0.01 ) (Fig. 6b). Similar to the VIIRSMODIS deviations, differences in blue bandpasses between SeaWiFS and MODIS were primarily responsible for cross sensor EVI differences and such differences became larger with increasing amounts of vegetation (negative EVI deviation in Fig. 6b). The smaller magnitudes of red and NIR bandpass deviations had a countering influence on overall EVI differences, with the red bandpass influencing EVI positively and the NIR bandpass causing a lower and negative bias on EVI across all vegetation amounts.

Differences in EVI values between SPOT-VGT and MODIS also exhibited a similar pattern as found with SeaWiFS-MODIS and VIIRS-MODIS, but with an entirely negative difference range from -0.035 to 0 (Fig. 6c). With these two sensors, however, there was less cross-sensor blue bandpass influence contributing to EVI differences, since SPOT-VGT and MODIS blue bandpass alignments were more similar (Fig. 1c). EVI differences between SPOT-VGT and MODIS were mostly associated with sensor NIR bandpass differences. Blue bandpass differences had a positive bias on EVI values and red bandpass differences a negative bias, thus red and blue bandpass differences countered one another, minimizing their influence on EVI.

\subsubsection{EVI2 band component deviations (2-band)}

We found greatly reduced differences in EVI2 values between VIIRS- MODIS and SeaWiFSMODIS due to the removal of the blue bandpass in EVI2, since it was the 'blue' band that

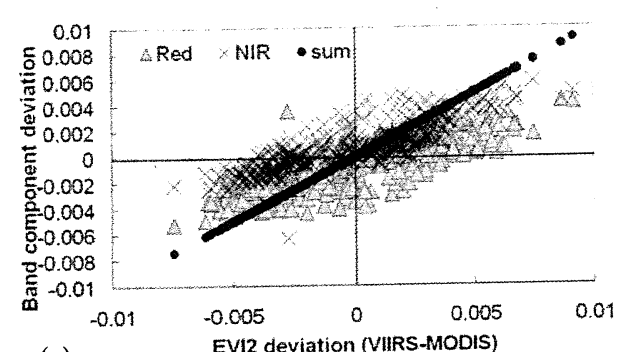

(a)
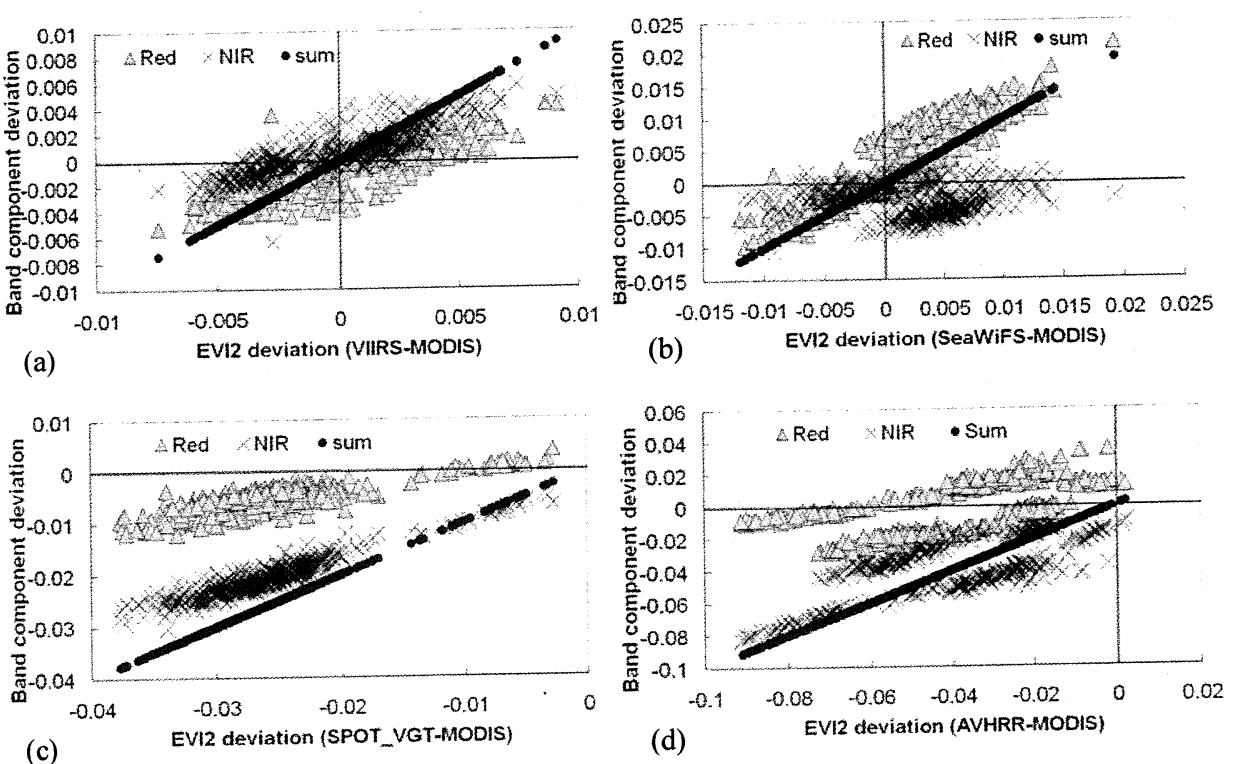

Fig. 7. Relationships between EVI2 deviations and EVI2 band component deviations for (a) VIIRSMODIS; (b) SeaWiFS-MODIS; (c) SPOT_VGT-MODIS; (d) AVHRR-MODIS comparisons. 
accounted for most 3-band EVI cross-sensor differences (Figs. 7a, b). EVI2 differences between VIIRS and MODIS were considerably reduced to a range of only 0.014 , relative to the range in EVI differences (0.050) (Fig. 7a). Both red and NIR bandpass differences, between these two sensors, similarly influenced the resulting EVI2 values, with a slight positive and a negative bias for both NIR and red bands. EVI2 differences between SeaWiFS and MODIS were also reduced, from a range of 0.026 , relative to EVI $(0.044)$, however, red bandpass differences were the primary determinant of EVI2 differences (Fig. 7b).

On the other hand, EVI2 variability between SPOT-VGT and MODIS was slightly greater, relative to the three-band EVI (Fig. 7c). In this case, the removal of the blue band in EVI2 did not improve cross-sensor variations, relative to EVI, since NIR bandpass deviations were the dominant factor responsible for EVI deviations between these two sensors. The removal of the blue band caused a slightly greater negative bias in EVI2 values, since the blue band between SPOT-VGT and MODIS had a countering effect to the red band, which thus helped reduce cross-sensor EVI differences (Figs. 6c, 7c). We also computed EVI2 differences between AVHRR and MODIS bandpasses and found very large differences ranging from -0.090 to 0 (Fig. $7 \mathrm{~d}$ ). This magnitude of differences was of the same order as NDVI differences, however, in contrast to the red bandpass controls on NDVI variations at higher vegetation amounts, EVI2 differences were more controlled by NIR bandpass differences (Figs. 5d, 7d).

In summarizing the variable effect of bandpass differences on cross-sensor VI variations, we averaged (arithmetic means) the effect of each bandpass deviation factor on observed VI differences between each sensor and MODIS over the entire range of vegetation amounts present in this study (Fig. 8). Overall, the differences between VIIRS and MODIS VIs were the smallest of all sensor pairs analyzed here with negligible variations in NDVI and EVI2 and larger variations in EVI, attributed to the blue band disparities (Fig. 8a).

VI variations between SeaWiFS and MODIS were relatively higher than those between VIIRS and MODIS, with EVI variations being the greatest due to the strong disparity between the sensor blue bands (Fig. 8b). Red band differences between SeaWiFS and MODIS resulted in a considerable positive bias in all of the three VIs, while NIR differences contributed a smaller negative bias. This resulted in SeaWiFS VI values higher than those of MODIS, except for EVI where the dominant negative effect of the blue band produced lower overall SeaWiFS EVI values. Note that the negative blue band bias was partially offset was the positive red band bias.

Bandpass differences between SPOT-VGT and MODIS resulted in an overall strong negative bias in all 3 VIs (Fig. 8c). Both red and NIR bandpass differences contributed a negative bias to SPOT-VGT VI values, with NIR bandpass differences being the most dominant. Blue bandpass differences positively biased the EVI values, counteracting the negative bias from the red and NIR bandpass differences, and resulting in lower overall EVI variations than EVI2 and NDVI variations.

Lastly, observed VI variations between AVHRR and MODIS were the largest of all sensors analyzed here, with strong negative biases observed in both NDVI and EVI2 (Fig. 8d). The resulting VI differences were almost entirely controlled by NIR bandpass differences, when averaged across the vegetation conditions analyzed here (Fig. 8d). Although red bandpass differences were negligible when averaged across the range of vegetation amounts, they were quite strong over particular vegetation amounts, resulting in their high standard deviations (e.g. the highest standard deviation occurred with red bandpass deviations of $\sim 0.035$ in NDVI). The strongest overall deviation was found between AVHRR and MODIS EVI 2 values. 

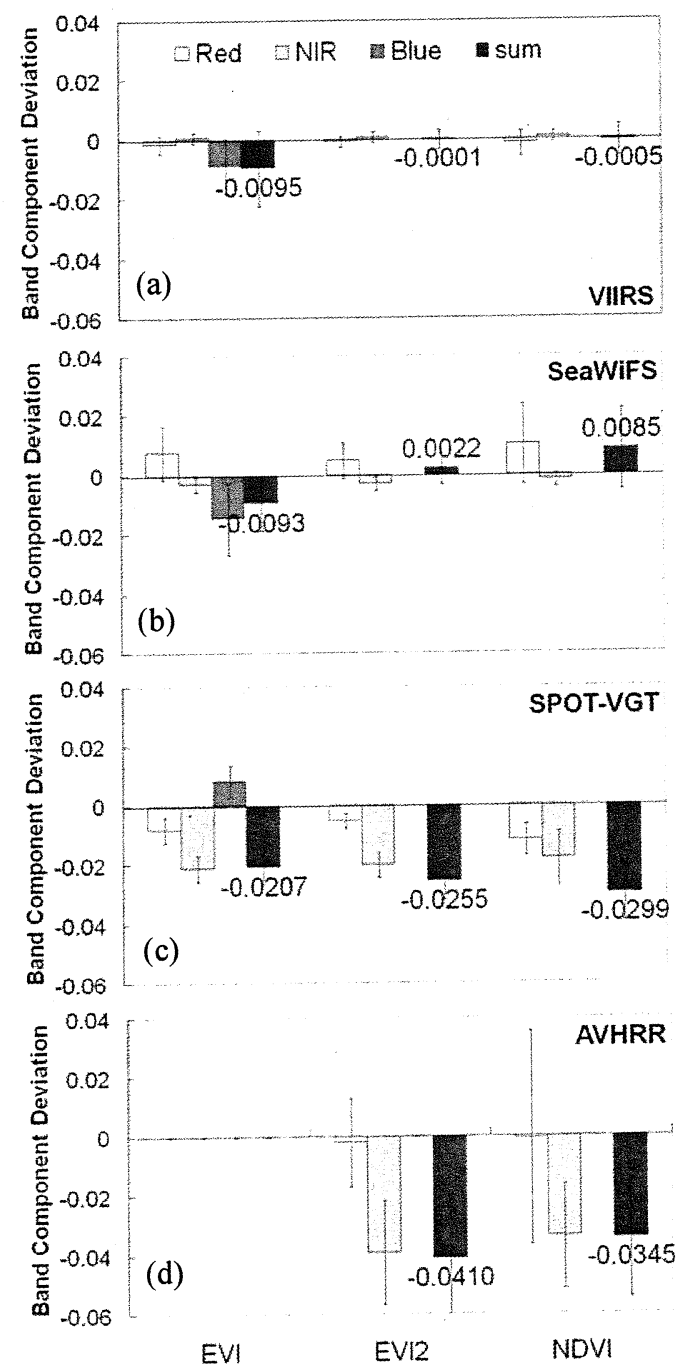

Fig. 8. Average (arithmetic mean) VI component deviations between MODIS and other sensors, (a) VIIRS, (b) SeaWiFS, (c) SPOT-VGT, and (d) AVHRR. Error bars indicate standard deviations of band component deviations.

\section{Conclusions}

In this study we conducted a spectral analysis of empirical cross-sensor relationships in reflectances and VIs using a series of Hyperion-convolved sensor bandpasses. As expected, there were strong linear empirical relationships found across corresponding sensor bandpass reflectances. However, when the highly correlated bandpass reflectances were combined, considerable cross-sensor VI differences were encountered that could potentially impede continuity in long-term vegetation studies based on multiple satellite missions. The large multiple sensor differences in EVI, EVI2, and NDVI were a result of cross- sensor reflectance deviations in slope and intercept. The application of empirical linear regression translation 
models from one sensor to another would partly remove some of these differences and improve VI compatibility across sensors by $50 \%$ or more. However, we found indications of land cover and soil dependencies on linear translation equations that may complicate and localize the use of empirical translation models. Further research on this topic is needed to assess to what extent cross sensor VI continuity relationships can be generalized.

We also conducted a decomposition analysis of bandpass contributions to observed crosssensor VI differences and assessed their combined integrative manner in influencing VI differences. Disparities in blue bandpasses were the primary cause of EVI differences between the MODIS and other course resolution sensors, including the upcoming VIIRS. The highest compatibility was between VIIRS and MODIS EVI2 while AVHRR NDVI and EVI2 were the least compatible to MODIS. We found complex interactions between bandpass differences and VIs in which individual bandpass differences reinforced or canceled each others influence on the resulting VI. Furthermore, these effects were VI equation dependent in addition to their sensor-dependencies.

Even though the EVI provides improved sensitivity in high biomass regions while minimizing soil and atmosphere influences, cross-sensor VI analysis shows increased difficulties in constructing long-term multiple sensor EVI records involving three bands. As found in this study, the EVI2 may achieve greater consistencies across sensors by minimizing the number of bands from three to two. An AVHRR-based EVI2 product may also improve upon the AVHRR-NDVI historical record by providing a greenness measure less reliant on red bandpass differences.

We conclude that the construction of long-term multiple sensor satellite products need to consider more than continuity in reflectances, but also the manner in which bandpass reflectances are combined in the generation of higher order products, including relatively simplistic VI equations. VI properties should be more thoroughly characterized spectrally to be better understand the influence of bandpass differences in order to achieve maximum compatibility for each sensor pair. This becomes especially crucial in using VIs for detection of climate signals.

\section{APPENDIX A:}

A.1 The partial derivatives of Enhanced Vegetation Index (EVI):

$$
\begin{aligned}
& \frac{\partial E V I}{\partial \rho_{N I R}}=2.5 \frac{7 \rho_{\text {Red }}-7.5 \rho_{\text {Blue }}+1}{\left(\rho_{\text {NIR }}+6 \rho_{\text {Red }}-7.5 \rho_{\text {Blue }}+1\right)^{2}} \\
& \frac{\partial E V I}{\partial \rho_{\text {Red }}}=-2.5 \frac{7 \rho_{\text {NIR }}-7.5 \rho_{\text {Blue }}+1}{\left(\rho_{\text {NIR }}+6 \rho_{\text {Red }}-7.5 \rho_{\text {Blue }}+1\right)^{2}} \\
& \frac{\partial E V I}{\partial \rho_{\text {Blue }}}=2.5 \frac{7.5\left(\rho_{\text {NIR }}-\rho_{\text {Red }}\right)}{\left(\rho_{\text {NIR }}+6 \rho_{\text {Red }}-7.5 \rho_{\text {Blue }}+1\right)^{2}}
\end{aligned}
$$

A.2 The partial derivatives of Enhanced Vegetation Index2 (EVI2):

$$
\begin{aligned}
\frac{\partial E V I 2}{\partial \rho_{N I R}} & =2.5 \frac{3.4 \rho_{\mathrm{Re} d}+1}{\left(\rho_{N I R}+2.4 \rho_{\mathrm{Re} d}+1\right)^{2}} \\
\frac{\partial E V I 2}{\partial \rho_{\mathrm{Re} d}} & =-2.5 \frac{3.4 \rho_{\text {NIR }}+1}{\left(\rho_{N I R}+2.4 \rho_{\mathrm{Re} d}+1\right)^{2}}
\end{aligned}
$$


A.3 The partial derivatives of Normalized Difference Vegetation Index (NDVI):

$$
\begin{aligned}
& \frac{\partial N D V I}{\partial \rho_{N I R}}=\frac{2 \rho_{\mathrm{Re} d}}{\left(\rho_{N I R}+\rho_{\mathrm{Red}}\right)^{2}} \\
& \frac{\partial N D V I}{\partial \rho_{\mathrm{Red}}}=\frac{-2 \rho_{N R R}}{\left(\rho_{N I R}+\rho_{\mathrm{Red}}\right)^{2}}
\end{aligned}
$$

where the reflectance $(\rho)$ is the average reflectance of MODIS and other sensors

\section{References}

[1] C. J. Tucker, J. E. Pinzon, M. E. Brown, D. A. Slayback, E. W. Pak, R. Mahoney, E. F. Vermote, and N. El Saleous, "An extended AVHRR 8-km NDVI dataset compatible with MODIS and SPOT vegetation NDVI data," Int. J. Rem. Sens. 26(20), 4485-4498 (2005) [doi:10.1080/01431160500168686].

[2] J. A. Eidenshink, "16-year time series of $1 \mathrm{~km}$ AVHRR satellite data of the conterminous United States and Alaska," Photogram. Eng. Rem. Sens. 72(9), 10271035 (2006).

[3] C. J. Tucker, "Red and photographic infrared linear combinations for monitoring vegetation," Rem. Sens. Environ. 8, 127-150 (1979) [doi:10.1016/00344257(79)90013-0].

[4] A. R. Huete, Y. Kim, P. Ratana, K. Didan, T. Miura, and Y. E. Shimabukuro, "Assessment of phenologic variability in Amazon tropical rainforests using hyperspectral and MODIS satellite data," Hyperspectral Remote Sensing of Tropical and Sub-Tropical Forests, M. Kalacska and A. Sanchez-Azofeifa, Eds., CRC Press, Boca Raton, FL (2008).

[5] N. C. Coops, T. A. Black, R. S. Jassal, J. A. Trofymow, and K. Morgenstern, "Comparison of MODIS, eddy covariance determined and physiologically modeled gross primary production (GPP) in a Douglas-fir forest stand," Rem. Sens. Environ. 107, 385-401 (2007) [doi:10.1016/j.rse.2006.09.010].

[6] F. A. Heinsch, M. Zhao, S. W. Running, J. S. Kimball, R. R. Nemani, K. J. Davis, P. V. Bolstard, B. D. Cook, A. R. Desai, D. M. Ricciuto, B. E. Law, W. C. Oechel, H. Kwon, H. Luo, S. C. Wolfy, A. L. Dunn, J. W. Munger, D. D. Baldocchi, L. Xu, D. Y. Hollinger, A. D. Richardson, P. C. Stoy, M. B. S. Siqueira, R. K. Monson, S. P. Burns, and L. B. Flanagan, "Evaluation of remote sensing based terrestrial productivity from MODIS using regional tower eddy flux network observations," IEEE Trans. Geosci. Rem. Sens. 44(7), 1908-1925 (2006) [doi:10.1109/TGRS.2005.853936].

[7] S. W. Running, R. R. Nemani, F. A. Heinsch, M. Zhao, M. Reeves, and H. Hashimoto, "A continuous satellite-derived measure of global terrestrial primary production," BioSci. 54(6), 547-560 (2004) [doi:10.1641/00063568(2004)054[0547:ACSMOG]2.0.CO;2].

[8] X. Gao, A. R. Huete, W. Ni, and T. Miura, "Optical-biophysical relationships of vegetation spectra without background contamination," Rem. Sens. Environ. 74, 609-620 (2000) [doi:10.1016/S0034-4257(00)00150-4].

[9] A. L. Schloss, D. W. Kicklighter, J. Kaduk, and U. Wittenberg, "Comparing global models of terrestrial net primary productivity (NPP): comparisons of NPP to climate and the normalized difference vegetation index (NDVI)," Global Change Biol. 5, 2534 (1999) [doi:10.1046/j.1365-2486.1999.00004.x]. 
[10] C. B. Field, J. T. Randerson, and C. M. Malmstrom, "Global net primary production: combining ecology and remote sensing," Rem. Sens. Environ. 51, 74-88 (1995) [doi:10.1016/0034-4257(94)00066-V].

[11] P. C. Sellers, "Canopy reflectance, photosynthesis and transpiration," Int. J. Rem. Sens. 6, 1335-1372 (1985) [doi:10.1080/01431168508948283].

[12] G. Asrar, M. Fuchs, E. T. Kanemasu, and J. L. Hatfield, "Estimating absorbed photosynthetic radiation and leaf area index from spectral reflectance in wheat," Agronomy J. 76, 300-306 (1984).

[13] R. E. Murphy and B. Reed, "NPP VIIRS update," 4th Global Vegetat. Works., Missoula, MT (2009) http://www.ntsg.umt.edu/VEGMTG/

[14] A. R. Huete, K. Didan, T. Miura, E. P. Rodriguez, X. Gao, and L. G. Ferreira, "Overview of the radiometric and biophysical performance of the MODIS vegetation indices," Rem. Sens. Environ. 83, 195-213 (2002) [doi:10.1016/S00344257(02)00096-2].

[15] T. N. Carlson and D. A. Ripley, "On the relation between NDVI, fractional vegetation cover, and leaf area index," Rem. Sens. Environ. 62, 241-252 (1997) [doi:10.1016/S0034-4257(97)00104-1].

[16] H. Q. Liu and A. Huete, "A feedback based modification of the NDVI to minimize canopy background and atmospheric noise," IEEE Trans. Geosci. Rem. Sens. 33(2), 457-465 (1995) [doi:10.1109/36.377946].

[17] A. R. Huete, H. Q. Liu, K. Batchily, and W. van Leeuwen, "A comparison of vegetation indices over a global set of TM images for EOS-MODIS," Rem. Sens. Environ. 59, 440-451 (1997) [doi:10.1016/S0034-4257(96)00112-5].

[18] C. Potter, S. Klooster, A. Huete, and V. Genovese, "Terrestrial carbon sinks for the United States predicted from MODIS satellite data and ecosystem modeling," Earth Interact. 11, 1-21 (2007) [doi:10.1175/EI228.1].

[19] A. R. Huete, K. Didan, Y. E. Shimabukuro, P. Ratana, S. R. Saleska, L. R. Hutyra, W. Yang, R. R. Nemani, and R. Myneni, "Amazon rainforests green-up with sunlight in dry season," Geophys. Res. Lett. 33, L06405 (2006) [doi:10.1029/2005GL025583].

[20] D. A. Sims, A. F. Rahman, V. D. Cordova, B. Z. El-Masri, D. D. Baldocchi, L. B. Flanagan, A. H. Goldstein, D. Y. Hollinger, L. Misson, R. K. Monson, W. C. Oechel, H. P. Schmid, S. C. Wofsy, and L. Xu, "On the use of MODIS EVI to assess gross primary productivity of North American ecosystems," J. Geophys. Res. 111, G04015 (2006) [doi:10.1029/2006JG000162].

[21] E. Swinnen and F. Veroustraete, "Extending the SPOT-VEGETATION NDVI time series (1998-2006) back in time with NOAA-AVHRR data (1985-1998) for Southern Africa," IEEE Trans. Geosci. Remote Sens. 46(2), 558-572 (2008) [doi:10.1109/TGRS.2007.909948].

[22] T. Miura, A. Huete, and H. Yoshioka, "An empirical investigation of cross-sensor relationships of NDVI and red/near-infrared reflectance using EO-1 Hyperion data," Rem. Sens. Environ. 100, 223-236 (2006) [doi:10.1016/j.rse.2005.10.010].

[23] W. J. D. van Leeuwen, B. J. Orr, S. E. Marsh, and S. M. Herrman, "Multi-sensor NDVI data continuity: uncertainties and implications for vegetation monitoring NDVI data continuity: uncertaintes [doi:10.1016/j.rse.2005.10.002].

[24] M. E. Brown, J. E. Pinzon, K. Didan, J. T. Morisette, and C. J. Tucker, "Evaluation of the consistency of long-term NDVI Time series derived from AVHRR, SPOTVegetation, SeaWiFS, MODIS, and Landsat ETM+ Sensors," IEEE Trans. Geosci. Rem. Sens. 44(7), 1787-1793 (2006) [doi:10.1109/TGRS.2005.860205].

[25] R. Fensholt, I. Sandholt, and S. Stisen, "Evaluating MODIS, MERIS, and VEGETATION vegetation indices using in situ measurements in a semiarid 
environment," IEEE Trans. Geosci. Rem. Sens. 44, 1774-1786 (2006) [doi:10.1109/TGRS.2006.875940].

[26] C. J. Tucker, J. E, Pinzon, M. E. Brown, D. A. Slayback, E. W. Pak, R. Mahoney, E. F. Vermonte and N. E. Saleous, "An extended AVHRR 8km NDVI dataset compatible with MODIS and SPOT vegetation NDVI data," Int. J. Rem. Sens. 26(20), 4485-4498 (2005) [doi:10.1080/01431160500168686].

[27] K. Gallo, L. Ji, B. Reed, J. Eidenshrink, and J. Dwyer, "Multi-platform comparisons of MODIS and AVHRR normalized difference vegetation index data," Rem. Sens. Environ.,99, 221-231 (2005) [doi:10.1016/j.rse.2005.08.014].

[28] K. Gallo, L. Ji, B. Reed, J. Dwyer, and J. Eidenshrink, "Comparison of MODIS and AVHRR 16-day normalized difference vegetation index composite data," Geophys. Res. Lett. 31, L07502 (2004) [doi:10.1029/2003GL019385].

[29] M. D. Steven, T. J. Malthus, F. Baret, H. Xu, and M. J. Chopping, "Intercalibration of vegetation indices from different sensor systems," Rem. Sens. Environ. 88, 412 422 (2003) [doi:10.1016/j.rse.2003.08.010].

[30] R. Bryant, M. S. Moran, S. A. McElroy, C. Holifield, K. J. Thome, T. Miura, and S. F. Biggar, "Data Continuity of Earth Observing 1 (EO-1) Advanced Land Imager (ALI) and Landsat TM and ETM+," IEEE Trans. Geosci. Rem. Sens. 41, 1204-1214 (2003) [doi:10.1109/TGRS.2003.813213].

[31] A. P. Trishchenko, J. Cihlar, and Z. Li, "Effects of spectral response function on surface reflectance and NDVI measured with moderate resolution satellite sensors," Rem. Sens. Environ. 81, 1-18 (2002) [doi:10.1016/S0034-4257(01)00328-5].

[32] A. Gitelson and Y. J. Kaufman, "MODIS NDVI optimization to fit the AVHRR data series - spectral consideration," Rem. Sens. Environ. 66, 343-350 (1998) [doi:10.1016/S0034-4257(98)00065-0].

[33] Y. Kim, A. R. Huete, Z. Jiang, and T. Miura, "Multisensor reflectance and vegetation index comparisons of Amazon tropical forest phenology with hyperspectral Hyperion data," Proc. SPIE 6679, 667906 (2007) [doi:10.1117/12.734974].

[34] S. J. Goetz, "Multi-sensor analysis of NDVI, surface temperature and biophysical variables at a mixed grassland site," Int. J. Rem. Sens. 18(1), $71-94$ (1997) [doi:10.1080/014311697219286].

[35] R. Fensholt, "Earth observation of vegetation status in the Sahelian and Sudanian West Africa: comparison of Terra MODIS and NOAA AVHRR satellite data," Int. J. Rem. Sens. 25, 1641-1659 (2004) [doi:10.1080/01431160310001598999].

[36] X. Xiao, Q. Zhang, S. Saleska, L. Hutyra, P. D. Camargo, S. Wofsy, S. Frolking, S. Boles, M. Keller, and B. Moore, "Satellite-based modeling of gross primary production in a seasonally moist tropical evergreen forest," Rem. Sens. Environ. 94, 105-122 (2005) [doi:10.1016/j.rse.2004.08.015].

[37] X. Xiao, Q. Zhang, B. Braswell, S. Urbanski, S. Boles, S. Wofsy, B. Moore, and D. Ojima, "Modeling gross primary production of temperate deciduous broadleaf forest using satellite images and climate data," Rem. Sens. Environ. 91, 256-270 (2004) [doi:10.1016/j.rse.2004.03.010].

[38] T. Miura, H. Yoshioka, K. Fujiwara, and H. Yamamoto, "Inter-comparison of ASTER and MODIS surface reflectance and vegetation index products for synergistic applications to natural resource monitoring," Sensors 8, 2480-2499 (2008) [doi:10.3390/s8042480].

[39] Z. Jiang, A. R. Huete, K. Didan, and T. Miura, "Development of a two-band enhanced vegetation index without a blue band," Rem. Sens. Environ. 112, 38333845 (2008) [doi:10.1016/j.rse.2008.06.006]. 
[40] A. R. Huete, T. Miura, Y. Kim, K. Didan, and J. Privette, "Assessments of multisensor vegetation index dependencies with hyperspectral and tower flux data," Proc. SPIE 6298, 629814 (2006) [doi:10.1117/12.681382].

[41] S. G. Ungar, J. S. Pearlman, J. A. Mendenhall, and D. Reuter, "Overview of the Earth Observing 1 (EO-1) mission," IEEE Trans. Geosci. Rem. Sens. 41(6), 11491159 (2003) [doi:10.1109/TGRS.2003.815999].

[42] E. F. Vermote, D. Tanre, J. L. Deuze, M. Herman, and J. Morcrette, "Second simulation of the satellite signal in the solar spectrum, 6S: an overview," IEEE Trans. Geosci. Rem. Sens. 35(3), 675-685 (1997) [doi:10.1109/36.581987].

[43] M. D. King, W. P. Menzel, Y. J. Kaufman, D. Tanre, B. C. Gao, S. Platnick, et al., "Cloud and aerosol properties, precipitable water, and profiles of temperature and water vapor from MODIS," IEEE Trans. Geosci. Rem. Sens. 41(2), 442-458 (2003) [doi:10.1109/TGRS.2002.808226].

[44] D. B. Gesch, Topographic data requirements for EOS global change research. U.S. Geological Survey Open-File Report, 94-626 (1994).

[45] P. R. Bevington and D. K. Robinson, Data Reduction and Error Analysis for the Physical Sciences, 3rd ed., McGraw-Hill, Boston (2003).

[46] T. Miura, A. Huete, and H. Yoshioka, "Evaluation of sensor calibration uncertainties on vegetation indices for MODIS," IEEE Trans. Geosci. Rem. Sens. 38(3), 13991409 (2000) [doi:10.1109/36.843034].

[47] E. F. Vermote, and N. Z. Saleous, "Operational atmospheric correction of MODIS visible to middle infrared land surface data in the case of an infinite Lambertian target," Earth Sci. Satel. Rem. Sens., 123-153 (2006).

Youngwook Kim is a research scientist at NTSG/FLBS, University of Montana. He received his BS in atmospheric science from Yonsei University, MS degrees in urban planning from Seoul National University in 1991 and 1995, respectively, and his $\mathrm{PhD}$ degree in soil, water, and environmental science from the University of Arizona in 2007. His current research interests is analyzing and integrating multiple satellite microwave remote sensing time series to construct calibrated, long-term global time series records of landscape freeze/thaw state dynamics for global climate change research as Earth System Data Record (ESDR), and creating terrestrial remote sensing products associated to global ecosystems.

Alfredo R. Huete is a Professor in the Department of Soil, Water and Environmental Science at the University of Arizona. He received his M.S. in Soil and Plant Biology from the University of California at Berkeley and Ph.D. in Soil and Water Science from the University of Arizona in 1984. He is a MODIS Science Team Member responsible for the development, implementation, and validation of the vegetation index products, and is part of the NPOESS Preparatory Project Science Team to evaluate vegetation indices as long-term environmental data records (EDRs). His interests are in satellite-based applications to study soil-vegetationclimate interactions, including phenology, tropical and arid ecosystems, drought, and land degradation.

Tomoaki Miura is an Assistant Professor in the Department of Natural Resources and Environmental Management at the University of Hawaii at Manoa. He received his M.S. degree in resource management from the University of Nevada, Reno in 1996 and his Ph.D. degree in soil, water, and environmental science from the University of Arizona in 2000. His current research activities include satellite data product continuity, tropical phenology, and societal impacts on land use changes in the Pacific region. 
Zhangyan Jiang is a post-doctor research associate at the Department of Soil, Water, and Environmental Science, University of Arizona. He received his BS from the Jiangxi Normal University, Nanchang, China, and his MS and $\mathrm{PhD}$ degrees both from Beijing Normal University, Beijing, China, all in geography, in 1998, 2002 and 2006, respectively. His research interests include optimization of remotely sensed vegetation indices, retrieval of vegetation biophysical parameters, and remote sensing of ecosystem dynamics and global changes. 
UlrichswebUlrich's Serials Analysis System SerialsSolutions

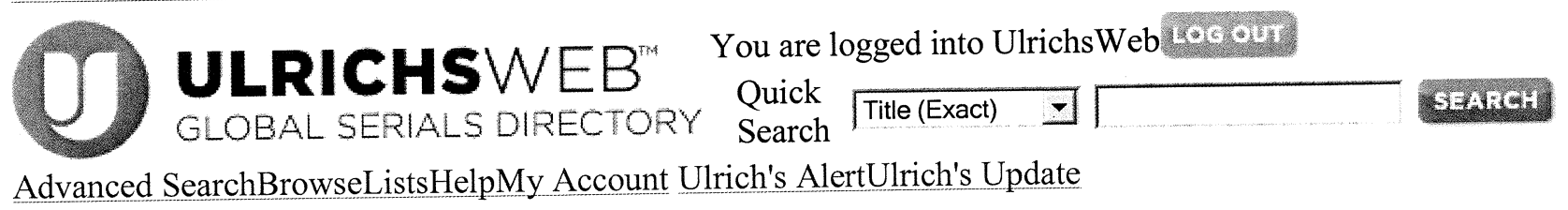

\section{Journal of Applied Remote Sensing}

$\checkmark$ BACK TO RESULTS

SEARCH MY LIBRARY'S CATALOG: ISSN Search I Title Search

\begin{tabular}{|c|c|c|c|}
\hline $\begin{array}{c}\text { Basic } \\
\text { Description }\end{array}$ & $\begin{array}{c}\text { Absiractingl } \\
\text { Indexing a Artere } \\
\text { Acees }\end{array}$ & $\begin{array}{l}\text { Publisher a } \\
\text { Ordering } \\
\text { Information }\end{array}$ & $\begin{array}{c}\text { Advertising Fights, } \\
\text { Demographics }\end{array}$ \\
\hline
\end{tabular}

JCF Wab 9 S.F.X

Click highlighted text for a new search on that item.

$\begin{array}{ll}\text { ISSN: } & 1931-3195 \\ \text { Title: } & \text { Journal of Applied Remote Sensing } \\ \text { Publishing Body: } & \text { S P I E - International Society for Optical Engineering } \\ \text { Country: } & \text { United States } \\ \text { Status: } & \text { Active } \\ \text { Start Year: } & 2007 \text { (Jan.) } \\ \text { Frequency: } & \text { Monthly (frequent updates) } \\ \text { Document Type: } & \text { Journal; Academic/Scholarly } \\ \text { Refereed: } & \text { Yes } \\ \text { Abstracted/Indexed: Yes } \\ \text { Media: } & \text { Online - full text } \\ \text { Language: } & \text { Text in English } \\ \text { Price: } & \text { USD 290 subscription per year to institutions } \\ & \text { (effective 2011) } \\ \text { Subject: } & \text { PHYSICS - OPTICS } \\ \text { Dewey \#: } & 535 \\ \text { Editor(s): } & \text { Dr. Wei Gao (Editor-in-Chief), Karolyn Labes (Managing } \\ & \text { Editor) } \\ \text { URL: } & \text { http://spie.org/X3636.xml } \\ \text { Description: } & \text { Covers the concepts, information, and progress of the remote } \\ & \text { sensing community, including past, current, and future remote } \\ & \text { sensing programs and experiments. }\end{array}$

$\triangle$ Back to Top

\begin{tabular}{|ll} 
Add this item to: & $\begin{array}{l}\text { Request this title: } \\
\text { I'd like to request this title. } \\
\text { Corrections: } \\
\text { Submit corrections to Ulrich's about this } \\
\text { title. } \\
\text { Publisher of this title? } \\
\text { If yes, click GO! to contact Ulrich's about } \\
\text { updating your title listings in the Ulrich's } \\
\text { database. }\end{array}$ \\
$\triangle$ Back to Top &
\end{tabular}

Copyright $(2011$ ProQuest LLC | Privacy Policy | Terms of Use | Contact Us 